\title{
Consultoria em patologia de partes moles: visão crítica de um consultor
}

\author{
Consultation in soft tissue pathology: critical view of a consultant
}

Fred Ellinger'; Marcello Franco ${ }^{2}$

abstract

Objective: The authors reviewed 500 cases of mesenchymal lesions from the private consultation files of one of them (F. E.) to evaluate the adequacy of sending of consultations by referring pathologists. Methodology: The information contained in the documents requesting the consultation as well as the material sent were evaluated. Results: It was observed that in high percentage of cases, there is absence of important information in the request such as: name of the patient, gross appearance of the lesion; depth of the lesion; clinical, surgical and pertinent laboratorial information; diagnosis of the referring pathologist and questions and doubts made by the referring pathologist. Conclusion: It was concluded that the referring pathologists could improve significantly the submission of the cases. To achieve this goal the authors propose a series of items in the form of a checklist to be verified by the referring pathologist when a case will be sent in consultation.

\begin{tabular}{l|l}
\hline \multicolumn{1}{c|}{ Unitermos } & resumo \\
Neoplasia & $\begin{array}{l}\text { Objetivos: Os autores revisaram } 500 \text { casos de lesões mesenquimais do arquivo de consultas da Faculdade } \\
\text { de Medicina de Marília enviados a um deles (F. E., patologista consultor) para avaliar a adequabilidade } \\
\text { Tecidos moles }\end{array}$ \\
$\begin{array}{l}\text { Patologia cirúrgica } \\
\text { Consultores }\end{array}$ & $\begin{array}{l}\text { solicitavam as consultas, bem como o tipo de material enviado. Resultados: Observou-se que há alto } \\
\text { percentual de ausência de informações importantes, tais como nome do paciente, aspecto macroscó- } \\
\text { pico da lesão, localização da lesão quanto à profundidade, informações clínicas, cirúrgicas e de exames } \\
\text { compultoria }\end{array}$ \\
$\begin{array}{l}\text { dúvidas pelo mesmontares pertinentes, hipótese diagnóstica do patologista consultante e formulação de questões, } \\
\text { a adequação do envio de suas consultas, e para tanto os autores propõem uma série de itens a serem } \\
\text { transmitidos ao consultor, por ocasião do envio da consulta, para que esta possa ser realizada da melhor } \\
\text { maneira possível, com real benefício para os pacientes. }\end{array}$
\end{tabular}

key words

Neoplasia

Soft tissue

Surgical pathology

Consultants

Consultation

1. Professor-doutor; chefe da disciplina de Patologia e chefe do Serviço de Anatomia Patológica e Citopatologia da Faculdade de Medicina de Marilia (SP). 


\section{Introdução}

Os tumores de tecidos moles constituem faceta difícil e fascinante da patologia cirúrgica. Muitos, como os lipomas e hemangiomas, são neoplasias comuns, com morfologia bem conhecida, sendo prontamente diagnosticadas pelo patologista cirúrgico geral(15). Por outro lado, os sarcomas de tecidos moles são neoplasias raras que têm grande impacto para os pacientes por suas implicações terapêuticas e prognósticas $(10,11,12,15)$. Patologistas gerais têm freqüentemente dificuldades para diagnosticar, precisamente, grande número de neoplasias de tecidos moles e, por esta razão, enviam o caso a consultores especializados ${ }^{(2,3,8)}$.

Um dos autores (F. E.) é patologista com interesse especial em patologia de partes moles, recebendo freqüentemente numerosas consultas sobre este assunto. Esse fato viabilizou o presente estudo.

\section{Objetivo}

Analisar criticamente a adequação do envio de consultas anatomopatológicas de lesões de partes moles, com o objetivo de traçar um roteiro ideal de envio dos casos.

\section{Material e métodos}

Como material de trabalho, foram utilizados 500 casos do arquivo de consultas do Serviço de Anatomia Patológica da Faculdade de Medicina de Marília, no período de 1995 a 1999, enviados a um dos autores (FE). Foram casos de lesões mesenquimais em tecidos moles, ossos e vísceras. As solicitações de consulta, bem como as cartas-resposta de cada caso, foram avaliadas quanto aos seguintes itens: procedência, nome do patologista consultante, dados de identificação do paciente (nome, idade, sexo); informações sobre: aspecto macroscópico da lesão, localização da lesão quanto à região anatômica e à profundidade, informações clínicas, exames complementares pertinentes, aspectos cirúrgicos da lesão e hipótese diagnóstica do cirurgião. Foi ainda avaliado se o consultante enviou uma hipótese diagnóstica e/ou diagnósticos diferenciais, se fez perguntas ao consultor e o tipo de material enviado.

\section{Resultados}

\section{Procedência}

Os casos vieram de todas as regiões do Brasil, sendo a grande maioria das Regiões Sudeste e Sul. Da Região Sudeste vieram 330 casos (66\%); da Sul, 140 (28\%); da Centro-Oeste, 25 (5\%); da Nordeste, 3 (0,6\%) e da Norte, 2 (0,4\%).
Os estados que mais contribuíram com casos foram São Paulo (298 - 59,6\%), Santa Catarina (66 - 13,2\%), Paraná (38 - 7,6\%), Rio Grande do Sul (36 - 7,2\%) e Minas Gerais $(29-5,8 \%)$.

Patologistas de outros estados da União também enviaram casos, num total de 131 patologistas consultantes.

\section{Identificação do paciente}

Foi fornecido o nome do paciente em 305 casos (61\%), a idade em 468 casos $(93,6 \%)$ e o sexo em 488 casos $(97,6 \%)$.

\section{Aspecto macroscópico e localização da lesão}

Em 248 casos (49,6\%), foram enviados dados macroscópicos na forma de descrição e/ou fotografia.

Em 487 casos (97,4\%), foi referida a localização anatômica da lesão e em 280 casos (56\%), a profundidade da lesão. Em 53 casos (10,6\%), a lesão localizava-se em uma víscera, principalmente do aparelho digestivo (20 casos). Os ossos foram sede das lesões em quatro casos.

\section{Informações clínicas, de exames complementares pertinentes, informações cirúrgicas e hipótese diagnóstica do cirurgião}

Em 271 casos (54,2\%), foram fornecidos informes clínicos, ora incompletos, ora detalhados e, em 50 casos $(10 \%)$, informes sobre exames complementares pertinentes. Informações cirúrgicas foram veiculadas em 80 casos (16\%) e a hipótese diagnóstica do cirurgião, em 63 casos (13\%).

\section{Hipótese diagnóstica do consultante e formulação de perguntas pelo patologista consultante}

A hipótese diagnóstica do consultante foi fornecida em 326 casos $(65,2 \%)$. Por vezes o consultante enviou apenas um diagnóstico, outras vezes mais de um ou uma lista de diagnósticos diferenciais. Em 50 casos (10\%), o consultante formulou uma ou mais perguntas.

\section{Material enviado}

Foram enviadas lâminas em 331 casos (66,2\%), blocos de parafina em 28 casos (5,6\%), lâminas e blocos em 138 casos $(27,6 \%)$ e tecido fixado e não-emblocado em três casos $(0,6 \%)$.

\section{Discussão}

A grande maioria dos casos proveio das regiões Sudeste e Sul, evidenciando que o consultor é mais conhecido como 
patologista especialista em patologia de tecidos moles nestas regiões geográficas pela sua atuação maior nos estados que as compõem.

Em 195 casos (39\%), não foi fornecido o nome do paciente pelo patologista consultante ao consultor, impedindo a identificação precisa do paciente-alvo da consulta. Este número elevado deve-se, talvez, ao fato de os consultantes freqüentemente não terem o hábito de enviar o nome do paciente nos documentos que acompanham o material. Muitos não enviam cópia do seu próprio laudo nem da requisição do exame anatomopatológico. É muito importante o envio do nome do paciente para a identificação precisa da consulta e para o registro do caso no serviço do consultor. Idade e sexo foram fornecidos na imensa maioria dos casos enviados.

Informações do aspecto macroscópico da lesão não foram fornecidas em 252 casos (50,4\%). Como estas informações são importantes para que o consultor chegue a um diagnóstico preciso e se o consultante as tem, não vemos razão pela qual não possam ser fornecidas ao consultor. Devem sempre ser enviadas, por serem, às vezes, muito úteis para o diagnóstico ${ }^{(1,}$ $9,14,15)$. Por exemplo, a descrição macroscópica de uma lesão fasciculada na superfície do corte faz pensar em diferenciação fibroblástica, muscular lisa e de bainha nervosa.

Apropriadamente, a informação da localização da lesão quanto à região anatômica foi enviada em $97,4 \%$ dos casos. No entanto, em 220 casos (44\%), não foi fornecida a informação da profundidade da localização da lesão, ou porque o consultante não tinha esta informação ou porque esqueceu de enviá-la. Este dado é muito importante não só para o consultor poder fazer o diagnóstico correto, mas também por ter implicações prognósticas. É amplamente conhecido que sarcomas em localização superficial têm prognóstico melhor dos que em localização profunda, abaixo da fáscia superficial(15). Uma neoplasia adiposa bem diferenciada, bem delimitada, com atipias nucleares, superficial, no subcutâneo do dorso de um homem idoso, pode ser um lipoma pleomórfico, enquanto que se esta mesma lesão for profunda, entre ou dentro de feixes musculares, deve ser classificada como tumor lipomatoso atípico ou lipossarcoma bem diferenciado, que pode recidivar localmente e, se sofrer desdiferenciação, metastatisar a distância( ${ }^{(6,13)}$.

Informes clínicos sobre o caso deixaram de ser enviados em 229 casos (45,8\%), percentual bastante alto, ou porque o consultante não os tinha ou porque não os repassou ao consultor. Dados clínicos concernentes à queixa do paciente, duração da evolução e os achados de exame físico são muito importantes e devem sempre ser fornecidos ao consultor para que ele possa ter melhores condições de fazer um diag- nóstico preciso da lesão. Por exemplo, uma lesão nodular superficial na face volar do antebraço de um adulto jovem, que apareceu subitamente e cresceu rapidamente em três semanas, faz pensar em fasciite nodular, mas se esta mesma lesão apareceu insidiosamente, cresceu lenta e progressivamente por muitos meses, provavelmente não é fasciite nodular, talvez possa ser um sarcoma fusocelular, com o qual ela tem diagnóstico diferencial histológico ${ }^{(5,15)}$.

Em poucos casos foram enviadas informações sobre exames complementares pertinentes, sobre o aspecto cirúrgico da lesão e sobre a hipótese diagnóstica do cirurgião. Esses dados, sempre que possível, devem ser fornecidos ao consultor porque ajudam no diagnóstico. Um exemplo da importância de informações cirúrgicas é saber se uma neoplasia maligna fusocelular retroperitoneal está ligada a uma víscera, como, por exemplo, ao rim. Caso o cirurgião diga que a mesma está conectada ao rim, deve ser incluído no diagnóstico diferencial do patologista um carcinoma sarcomatóide, além de sarcoma primário renal ou sarcoma retroperitoneal acometendo o rim secundariamente ${ }^{(15)}$.

Em 174 casos (34,8\%), o consultante não enviou nem sua hipótese diagnóstica, nem uma relação de diagnósticos diferenciais. O envio dessas informações é extremamente importante para o consultor saber se houve concordância ou discordância discreta ou acentuada entre o seu diagnóstico e o do consultante, para saber qual é a dificuldade e poder fazer considerações formativas sobre o diagnóstico e os diagnósticos diferenciais do consultante. Poderá dizer por que acha que o diagnóstico correto é o seu e não o do consultante e por que afasta as entidades do diagnóstico diferencial do mesmo. Desta forma, o consultor em sua carta -resposta pode inserir informações de caráter educacional que visam aprimorar a capacidade diagnóstica de quem envia a consulta. A hipótese diagnóstica e os diagnósticos diferenciais devem sempre ser enviados.

Em apenas 50 casos (10\%) o consultante formulou algum tipo de pergunta ou perguntas, que foram as mais variadas possíveis. É fundamental que o consultante expresse suas dúvidas sob a forma de perguntas para que o consultor possa ajudá-lo, respondendo às questões. É outra forma de permitir que a carta-resposta seja um instrumento educacional.

O material da lesão enviado, na grande maioria dos casos, foi suficiente e representativo. Em alguns casos, houve necessidade da solicitação de mais material, como novas lâminas ou blocos de parafina, para estudo imunoistoquímico, melhor avaliação da lesão ou envio do caso a outros patologistas mais experientes, para que fizessem 0 controle de qualidade do patologista consultor. 


\section{Conclusão}

O alto percentual de ausência de envio de informações importantes, tais como nome do paciente, aspecto macroscópico da lesão, localização da lesão quanto à profundidade, informações clínicas de exames complementares e cirúrgicas e hipótese diagnóstica do consultante, permite concluir que os patologistas consultantes poderiam melhorar muito o envio de casos em consulta ${ }^{(4,7)}$. Para que se possa oferecer a melhor consulta, o patologista consultante deve enviar ao consultor, por carta e/ou cópia da requisição e cópia do seu laudo anatomopatológico, os seguintes dados:

1. nome completo do paciente;

2. sexo, idade, raça e outros dados identificatórios relevantes;

3. localização precisa da lesão quanto à região anatômica e profundidade;

4. informações clínicas, de exames complementares e cirúrgicas pertinentes (sintomas, duração da doença, achados de exame físico, de exames de imagem, de exames laboratoriais e achados cirúrgicos);

5. informações sobre citologias e/ou material cirúrgico prévio, se pertinentes;
6. hipótese diagnóstica do cirurgião;

7. aspecto macroscópico da lesão;

8. hipótese diagnóstica do patologista consultante e seus diagnósticos diferenciais;

9. razão da consulta e perguntas a serem respondidas pelo patologista consultor;

10. uma lâmina corada rotineiramente de cada corte feito da peça (recomenda-se pelo menos um corte por cada centímetro do maior diâmetro da lesão);

11. um ou dois blocos representativos da lesão (este material poderá ser devolvido);

12. resultado de outros estudos realizados: histoquímica, imunoistoquímica, etc.

13. endereço completo, com números de telefone, de fax e endereço eletrônico;

14. indicação da urgência da consulta;

15. se há áreas específicas nas lâminas em que há dúvidas, estas áreas devem ser marcadas e as dúvidas expressas na carta;

16. se for o caso, informações de como cobrar a consulta.

Estes dados podem ser guardados na gaveta ao lado do microscópio sob forma de check list para serem conferidos na hora de enviar a consulta.

\section{Referências}

I.ALLEN, P.W. Desmoids with sarcomatous change and metastasis. Histopathology, v. 27, p. 199-202, 1995.

2. ALVERGARD,T.A.; BERG, N. O. Histopathology peer review of high-grade soft tissue sarcoma: the Scandinavian Sarcoma Group experience. J Clin Oncol, v. 7: p. $1845-$ $51,1989$.

3.ARBISER,Z.K.; FOLPE,A. L;WEISS, S.W. Consultative (expert) second opinions in soft tissue pathology: analysis of problem-prone diagnostic situations. Am J Clin Pathol, v. I I 6, p. 473-6, 200 I.

4. ASSOCIATION OF DIRECTORS OF ANATOMIC AND SURGICAL PATHOLOGY (USA). Recomendation of the Association of Diretors of Anatomic and Surgical Pathology. Part II. Consultations in Surgical Pathology. Hum Pathol, v. 24, p. 69I-2, 1993.

5. BERNSTEIN, K. E.; LATTES, R. Nodular (pseudosarcomatous) fasciitis, a non-recurrent lesion: clinicopathologic study of I 34 cases. Cancer, v. 49, p. 1668-78, 1982.

6. EVANS, H. L.; SOULE, E. H.;WINKELMAN R. K. Atypical lipoma, atypical intramuscular lipoma, and well differentiated retroperitoneal liposarcoma. A reappraisal of 30 cases formely classified as well differentiated liposarcoma. Cancer, v. 43: p. 574-84, 1979.

7. FRANCO, M. Consultoria em anatomia patológica. Sociedade Brasileira de Patologia (SPB), São Paulo, 1995.

8. HARRIS, M. et al. Sarcomas in North West England. I. Histopathological peer review. Br J Cancer, v. 64, p. 315-20, 1991.

9. HASHIMOTO, H.;TSUNEYOSHI, M.; ENJOJI, M. Malignant smooth muscle tumors of the retroperitoneum and mesentery: a clinicopathologic analysis of 44 cases. J Surg Oncol, v. 28, p. 177-86, 1985.

10. PARKER, S.L. et al. Cancer statistics. CA Cancer J Clin, v. 46, p. 5-27, 1996.

I I. RYDHOLM,A. Management of patients with soft tissue tumors: strategy developed at a regional oncology center. Acta Orthop Scand Suppl, v. 203, p. 13-77, 1983.

12. RYDHOLMA. et al. Epidemiology of soft tissue sarcoma in the locomotor system: a retrospective population-based study of the interrelationships between clinical and morphological variables. Acta Pathol Microbiol Immunol Scand [A], v. 92 p. 363-74, 1984.

13. SHMOOKLER, B. M.; ENZINGER, F. M. Pleomorphic lipoma: a benign tumor simulating liposarcoma: a clinicopathologic analysis of 48 cases. Cancer, v. 47, p. 126-33, 1981.

I4. STOUT, A. P. Fibrosarcoma: the malignant tumor of fibroblasts. Cancer, v. I, 30-2, 1948

15. WEISS, S. W.; GOLDBLUM, J. R. Soft tissue tumors. 4. ed. St Louis: Mosby, 2001.

Endereço para correspondência

Marcello Franco Departamento de Patologia Edifício Lemos Torres - $1^{\circ}$ andar Escola Paulista de Medicina/Unifesp Rua Botucatu 740 - Vila Clementino CEP 04023-900 - São Paulo-SP mfranco@patologia.epm.br 